\title{
Rubidium marking of Aphidius rhopalosiphi (Hymenoptera: Braconidae) on Sitobion avenae (Hemiptera: Aphididae) reared on a diet supplemented with $\mathrm{RbCl}$
}

\author{
FréDÉRIC MURATORI, DeLPHINE PERREMANS and ThIERry HANCE*
}

\begin{abstract}
Centre de recherches sur la biodiversité, Unité d'écologie et biogéographie, Université Catholique de Louvain, 4-5 place croix du
\end{abstract} sud, B-1348, Louvain-la-Neuve, Belgium

Key words. Braconidae, Aphididae, rubidium, markers, diet, $\mathrm{RbCl}$, Aphidius rhopalosiphi, Sitobion avenae

\begin{abstract}
Markers are essential to study movements of insects in their natural habitat. Among the available techniques, trace elements may be applied to insects as small as parasitoids. Rubidium is the most common element used for marking insects. In this study, we propose a simple marking technique for Aphidius rhopalosiphi De Stefani Perez with Rb, when reared on the grain aphid Sitobion avenae Fabricius (Hemiptera: Aphididae) marked on a $\mathrm{RbCl}$ incorporated diet. Our results show that the rubidium in an artificial diet is transferred to the aphid and eventually to the parasitoid. The content in rubidium marking did not differ between genders. The aphids stung by a marked parasitoid could not be distinguished from unmarked aphids on the basis of their rubidium content. There were no effects of rubidium on size, fecundity, longevity and sex ratio of the parasitoid, but the marked individuals emerged significantly later than the unmarked. We did not detect differences concerning host acceptance by marked and unmarked parasitoids. This technique may be applicable to other aphidophagous insects after some preliminary evaluations.
\end{abstract}

\section{INTRODUCTION}

The analysis of insect movements in their natural habitats is often needed to understand their dispersal capacity, mating behaviour, territoriality and foraging strategy. For this purpose several marking techniques are available such as colour marking, labelling, partial mutilation, elytra puncturing, etc. However, no marker has been revealed to be universal and the respective advantages are sometimes counterbalanced by drawbacks and side effects on the marked individuals (for a review see Hagler \& Jackson, 2001). According to Southwood (1969), a good marking method should not affect the insect behaviour and the mark should last as long as possible. Moreover, marked insects should be able to mix without distinction with unmarked individuals. Labels and partial mutilations can only be used for large insects and often present important side effects. Ink and paint may also modify the insect behaviour or can be toxic. Radioactive-isotope marking has a reduced applicability due to environmental concerns. Alternatively to the radioisotope technique, rare or trace elements are more increasingly used as markers (Fernandes et al., 1997; Qureshi et al., 2004) and are among the few ones usable for small insects such as parasitoids (Hagler \& Jackson, 2001). Berry et al. (1972) were the first to propose rubidium $(\mathrm{Rb})$ as a useful element for marking. They argued that (1) rubidium is widely spread in the earth crust but in low natural abundance, (2) it is a non-radioactive element and therefore does not have the environmental drawbacks of radioactive isotopes, (3) it is nearly non-toxic for insects, (4) it can be easily administered, and (5) analyses are rather simple. Rubidium is chemically close to potassium and can partly replace it in living organisms (Stimmann et al., 1973).

Insect marking can be easily done spraying onto the individuals a solution containing the trace element. However, an internal marking is usually preferred. The technique proposed by Berry et al. (1972) consisted of spraying a solution of $\mathrm{RbCl}$ on the host plant to mark Trichoplusia ni (Lepidoptera: Noctuidae). Frazer \& Raworth (1974) produced marked aphids by growing the host plant in a hydroponic solution containing $\mathrm{RbCl}$. Similarly, Payne \& Wood (1984) directly injected rubidium to the trunk of a tree in order to mark Cydia caryana (Lepidoptera: Tortricidae).

In this study, we incorporated rubidium into an artificial diet for the grain aphid Sitobion avenae Fabricius (Hemiptera: Aphididae) in order to mark its parasitoid Aphidius rhopalosiphi De Stefani Perez (Hymenoptera: Braconidae). Different $\mathrm{RbCl}$ concentrations in the diet were used and related with rubidium concentrations in the aphids and adult parasitoids of first and second generations. Potential side effects on the parasitoid were also quantified regarding to longevity, development times, behaviour and sex ratio.

\section{MATERIAL AND METHODS}

\section{Aphid and parasitoid rearing}

Aphids were reared in Petri dishes on an artificial diet consisting of a mixture of sucrose, amino acids, vitamins and mineral salts (composition in Auclair, 1965), as described by Cambier et al. (2001) under constant conditions: $20 \pm 1{ }^{\circ} \mathrm{C}, 60 \%$ RH, 16L : 8D. Parasitoids were reared in cages on the same aphid species on wheat plants as described by Legrand et al. (2004).

\footnotetext{
* corresponding author; e-mail: hance@ecol.ucl.ac.be
} 


\section{Marking technique}

After some preliminary experiments, two rubidium concentrations were tested: 1.3 and $2.4 \mathrm{~g} \mathrm{RbCl}$ per litre of aphid diet (1300 and $2400 \mathrm{ppm} \mathrm{Rb}$ ). Weighed quantities of $\mathrm{RbCl}$ were dissolved in $1 \mathrm{ml}$ of artificial diet to obtain a concentrated base solution subsequently used to produce the desired concentrations. An artificial diet without $\mathrm{RbCl}$ was used as control. Fifteen adult aphids were placed on the artificial diet in the Petri dish and allowed to reproduce for two days. Three days later, 20 second and third instar progeny were separated into a new Petri dish with one female parasitoid (two days old and mated). To prevent superparasitism, aphids were removed from the Petri dish when an ovipositor contact was observed. Simultaneously, 20 unparasitized aphids were kept for two more days on the artificial diet before being processed to analyse their rubidium content.

\section{Rubidium detection}

Aphids were placed into a glass test tube (one individual per sample) and $25 \mu \mathrm{l}$ of hydrogen peroxide $\left(\mathrm{H}_{2} \mathrm{O}_{2}\right)$ suprapur $30 \%$ and $25 \mu 1$ of nitric acid $\left(\mathrm{HNO}_{3}\right)$ suprapur $65 \%$ were added for mineralisation. Samples were heated at $62^{\circ} \mathrm{C}$ for $2 \mathrm{~h}$ and were then diluted to $5 \mathrm{ml}$ with deionised water. Rubidium was detected and quantified using a graphite furnace (Atomic Absorption Spectrometry, SpectrAA 300, Varian) at the "Unité des sciences du sol" (Université Catholique de Louvain, Belgium).

Parasitoids were mineralised as described above except that $25 \mu 1$ of $\mathrm{KCl} 1 \%$ were added before being heated. This reduced interference with other elements and allowed better detection. The samples were subsequently analysed using a plasma torch (Emission Spectrometry, Iris Avantage, Thermo Jarrel Ash Corporation). This technique has a lower detection threshold than the graphite furnace. Unmarked aphids and parasitoids were used as control.

\section{Efficiency of the marking method}

To evaluate the persistence of the assimilated $\mathrm{Rb}$ in the insects, 5-days old aphids fed with the marked artificial diet were analysed $(\mathrm{n}=10,19$ and 18 for $0,1.3,2.4 \mathrm{mg} \mathrm{RbCl} / \mathrm{ml}$ of diet, respectively). In addition, adult parasitoids that developed on marked aphids were tested for $\mathrm{Rb}$ content $(\mathrm{n}=10$ for each treatment). To determine the possibility of trans-generational marking, marked parasitoids were allowed to parasitize unmarked aphids. The rubidium content of these parasitized aphids $(\mathrm{n}=10)$ was measured the same day they were parasitized. Log transformed data were analysed using a generalised linear model (SASv8, Sas institute) followed by a StudentNewman-Keuls test for multiple comparisons between the three rubidium concentrations tested $(0,1.3,2.4 \mathrm{mg} \mathrm{RbCl} / \mathrm{ml}$ of diet).

\section{Side effects of the marking}

\section{Development times}

Marked aphids were produced as described above with an artificial diet containing 1.3 or $2.4 \mathrm{mg} \mathrm{RbCl} / \mathrm{ml}$. Unmarked aphids were fed with the same artificial diet devoid of rubidium. Aphids were presented to a female parasitoid (20 aphids/ female). Once stung, aphids were removed from the Petri dishes and placed on a new diet until the emergence of adult parasitoid. This was done under controlled conditions: $19 \pm 1{ }^{\circ} \mathrm{C}, 50 \% \mathrm{RH}$, $16 \mathrm{~L}: 8 \mathrm{D}$. The number of mummies and emerged parasitoids were recorded daily for 40 individuals for each rubidium concentration.

\section{Longevity of the marked parasitoids}

Once emerged, parasitoid adults were isolated and sexed. At least 20 individuals from each sex were monitored for each rubidium concentration, except in the case of females produced on the highest rubidium content $(\mathrm{n}=13)$. Individuals were kept in Petri dishes, fed with a solution of water:honey $1: 1$, under the same conditions as mentioned above. The number of survivors were recorded daily until all individuals were dead. Data were analysed using LIFETEST procedure with the life table method (SAS, Sas institute).

\section{Behavioural analyses}

In order to test the aphid acceptance by the marked parasitoids, marked and unmarked females ( 2 days old and naïve) were placed individually for $15 \mathrm{~min}$ into a Petri dish containing 15 second instar aphids. Each stung aphid was immediately replaced by a new one. The number of antennal contacts, abdominal bendings and ovipositor contacts made by the parasitoid were recorded. The observation finished when the female reached 30 antennal contacts on the aphids; 11 females were observed for each tested condition.

\section{Sex ratio of the marked parasitoids}

Marked and unmarked mummies produced as described above were isolated. At emergence, each female was placed with one unmarked male (to avoid the influence of rubidium on males). For each concentration of rubidium, mated females were subsequently placed in a contact chamber containing 70 aphids on wheat seedlings (10 repetitions). Ten days later, mummies were isolated in Petri dishes and checked for emergence. The offspring sex ratio was recorded. Mummification and sex ratio were compared using the GLM procedure with one fixed factor ( $\mathrm{Rb}$ content) after checked for normality of the data distribution. Data with abnormal distributions were analysed with the Kruskal-Wallis test.

\section{RESULTS}

\section{Rubidium content in aphids and parasitoid}

The rubidium content of marked aphids was significantly higher than in control aphids $\left(\mathrm{X}^{2}=25.36\right.$; d.f. $=2$; $\mathrm{p}=0.0001)$, the highest concentrations being found in aphids reared on the diet with the highest rubidium dose (Fig. 1). This pattern was conserved for the parasitoid $\left(\mathrm{F}_{(1,34)}=22.52 ; \mathrm{p}<0.0001\right)$ without differences in rubidium content between genders $\left(\mathrm{F}_{(1,34)}=1.48 ; \mathrm{p}=\right.$ 0.2318) (Fig. 1).

A very small amount of rubidium was transmitted into aphids stung by a marked parasitoid (means \pm S.E.: 0.37 $\pm 0.1 \mathrm{ppb}$ for the control; $0.30 \pm 0.1 \mathrm{ppb}$ for the 1.3 $\mathrm{mg} / \mathrm{ml}$ treatment; $0.67 \pm 0.2$ for the $2.4 \mathrm{mg} / \mathrm{ml}$ treatment). These quantities were not significantly different across treatments $\left(\mathrm{X}^{2}=3.649 ; \mathrm{p}=0.1612\right)$. Moreover, a large number of samples were under the detection threshold of the plasma torch.

\section{Effect of RbCl on parasitoid}

Development time to mummification and adult emergence increased regardless of sex in both treatments with $\mathrm{RbCl}$ (Fig. 2). Marked individuals took longer to develop than unmarked individuals for both concentrations of $\mathrm{RbCl}$. For each treatment vs control comparison, $\mathrm{X}^{2}$ tests revealed significant differences $(\mathrm{p}<0.05$ for each test). This trend occurred for the times until mummification $\left(\mathrm{X}^{2}\right.$ $=31.57$ and $\mathrm{X}^{2}=26.51$ for 1.3 and $2.4 \mathrm{mg} \mathrm{RbCl} / \mathrm{ml}$ diets, respectively) and emergence of males $\left(\mathrm{X}^{2}=9.5\right.$ and $\mathrm{X}^{2}=$ 37.2 for 1.3 and $2.4 \mathrm{mg} \mathrm{RbCl} / \mathrm{ml}$ diets, respectively) and 


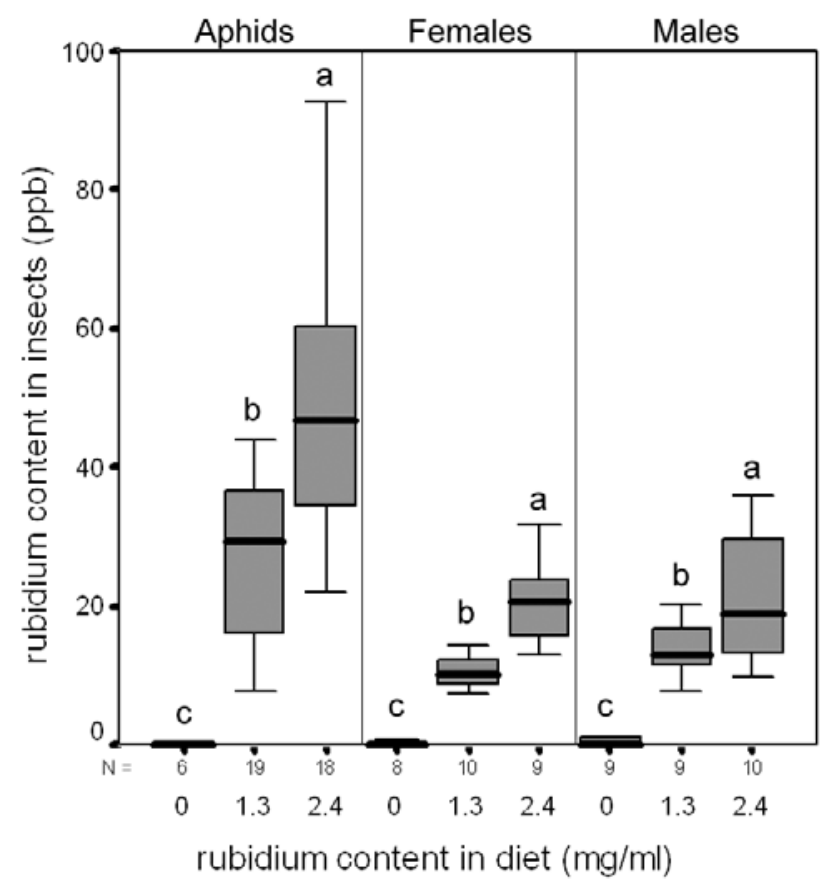

Fig. 1. Rubidium content in aphids and in male and female parasitoids. Treatments labels: $0=$ control diet; $1.3=$ diet supplemented with $1.3 \mathrm{mg} / \mathrm{ml}$ of $\mathrm{RbCl} ; 2.4=$ diet supplemented with $2.4 \mathrm{mg} / \mathrm{ml}$ of $\mathrm{RbCl}$. Boxplots show the quartiles, the thin lines show the median, scales show the maximum and minimum values. Boxplots with different letters are significantly different.

females $\left(\mathrm{X}^{2}=7.62\right.$ and $\mathrm{X}^{2}=19.8$ for 1.3 and $2.4 \mathrm{mg}$ $\mathrm{RbCl} / \mathrm{ml}$ diets, respectively).

However, there were no significant effects of $\mathrm{RbCl}$ on the emergence rate (number of adults emerged / number of mummies). Emergence reached $0.64,0.67$ and 0.55 for $0,1.3$ and $2.4 \mathrm{mg} \mathrm{RbCl} / \mathrm{ml}$ diets, respectively $\left(\mathrm{F}_{(2,23)}=\right.$ $1.01 ; \mathrm{p}=0.3802)$. There were no significant differences across treatments for mummification rate $\left(\mathrm{F}_{(2,18)}=1.58 ; \mathrm{p}\right.$ $=0.2324)$, emergence rate $\left(\mathrm{X}_{(2)}=3.6782 ; \mathrm{p}=0.1590\right)$ and sex ratio $\left(\mathrm{F}_{(2,17)}=0.91 ; \mathrm{p}=0.4227\right)$ of the second generation of the parasitoids (Table 1).

Similarly, the Log-rank test (PROC LIFETEST) did not reveal any effect of $\mathrm{RbCl}$ on longevity $\left(\mathrm{X}_{(2)}^{2}=2.0596\right.$; $\mathrm{p}$ $=0.3571)$. Differences were found according to the sex of the parasitoid; females lived longer than males, irrespectively of their rubidium content $\left(\mathrm{X}_{(1)}^{2}=4.5181 ; \mathrm{p}=\right.$ 0.033). Fig. 3 shows the survival curves for male and female parasitoids.

TABLE 1. Effect of $\mathrm{RbCl}$ content on mummification, emergence rates and sex ratio ( $\%$ of male). $0=$ control diet; $1.3=$ diet supplemented with $1.3 \mathrm{mg} / \mathrm{ml}$ of $\mathrm{RbCl} ; 2.4=$ diet supplemented with $2.4 \mathrm{mg} / \mathrm{ml}$ of $\mathrm{RbCl}$.

\begin{tabular}{cccc}
\hline $\begin{array}{c}\mathrm{RbCl} \text { content } \\
\text { in diet }(\mathrm{mg} / \mathrm{ml})\end{array}$ & $\begin{array}{c}\text { mummification } \\
\text { rate }\end{array}$ & $\begin{array}{c}\text { emergence } \\
\text { rate }\end{array}$ & sex ratio \\
\hline 0 & 51.4 & 92.5 & 50.7 \\
1.3 & 56.4 & 93.6 & 51.8 \\
2.4 & 38 & 92.9 & 59.4 \\
$\mathrm{P}$ value & $0.2324^{\mathrm{ns}}$ & $0.159^{\mathrm{ns}}$ & $0.4227^{\mathrm{ns}}$ \\
\hline
\end{tabular}
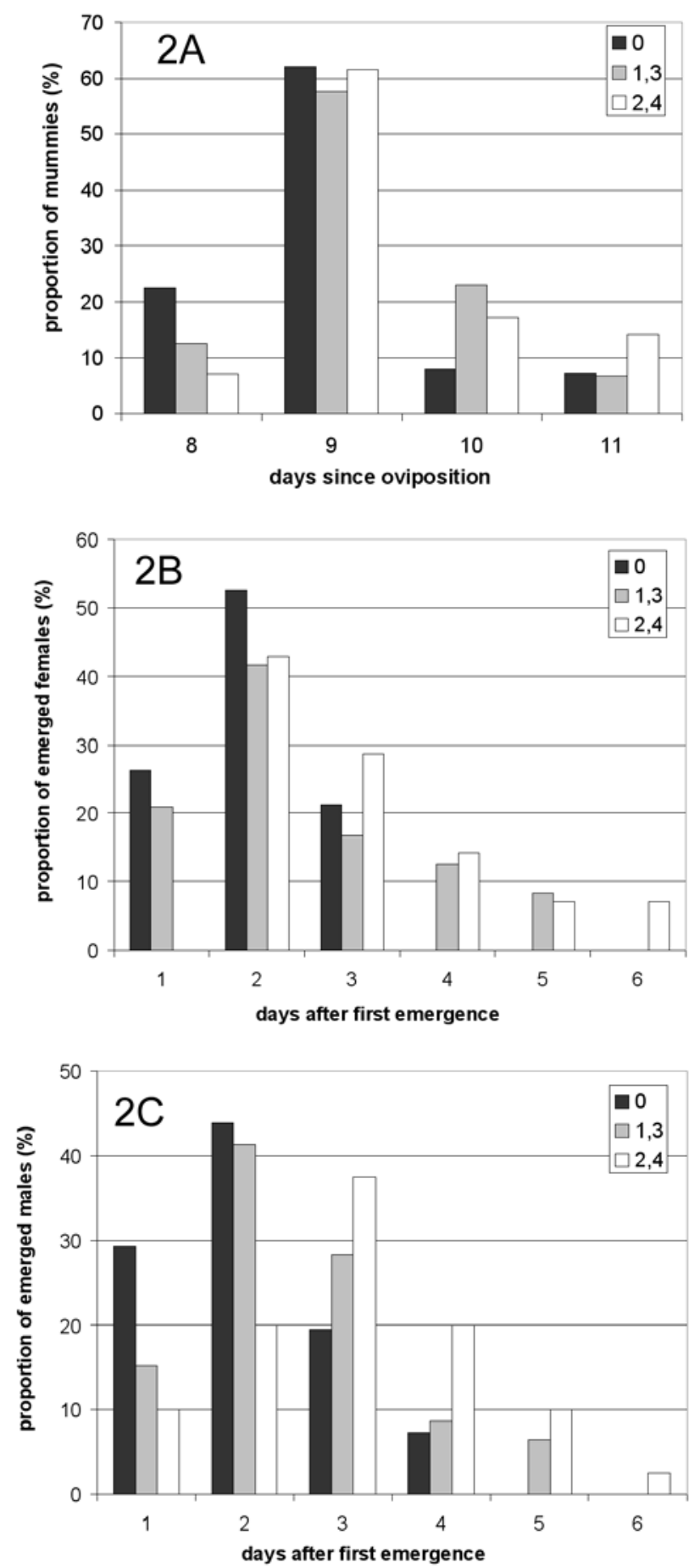

Fig. 2. Development times of $A$. rhopalosiphi. 2A: duration to mummies formation, $2 \mathrm{~B}$ : duration to female and $2 \mathrm{C}$ male emergence. $0=$ control diet; $1.3=1.3 \mathrm{mg} / \mathrm{ml} \mathrm{RbCl} ; 2.4=$ diet added with $2.4 \mathrm{mg} / \mathrm{ml} \mathrm{RbCl}$.

Both host acceptance $\left(\mathrm{F}_{(30,2)}=0 ; \mathrm{p}=0.9995\right)$ and stinging $\left(\mathrm{F}_{(30,2)}=0.46 ; \mathrm{p}=0.6348\right)$ ratios were similar across treatments (Table 2).

\section{DISCUSSION}

Stimmann (1974) considered that insects were marked when their rubidium content reached at least the mean plus 3 times the standard deviation compared to control 



Fig. 3. Survival curves of females (3A) and males (3B) related to rubidium content. $0=$ control diet; $1.3=$ diet supplemented with $1.3 \mathrm{mg} / \mathrm{ml}$ of $\mathrm{RbCl} ; 2.4=$ diet supplemented with $2.4 \mathrm{mg} / \mathrm{ml}$ of $\mathrm{RbCl}$.

insects. In this study, all aphids analysed could be thus considered as "marked". Besides, in our experiment, the rubidium content in the insects is correlated with its content in the diet. Frazer \& Raworth (1974) noted that the marking decreases when pea aphids, Acyrthosiphon pisum (Harris), were transferred from rubidium marked to unmarked diet. Guillebeau et al. (1993) reported that rubidium levels in green peach aphid, Myzus persicae (Sulzer), and potato aphid, Macrosiphum euphorbiae (Thomas), were reduced by nearly $90 \%$ after a five days removal from marked tomato plants. Van Steenwyk (1991) postulated that the marking detectability depends (1) on the time spent on the rubidium supplemented diet and (2) on the quantity of ingested food after transfer to a control diet. In our study, all aphids were 5-days old. It is expected that adult aphids would have a higher rubidium content. Frazer \& Raworth (1974) analysed adult aphids that spent their life on marked diet. Nevertheless, we can imagine that the biological incorporation of the rubidium in insect is limited to a maximum threshold that would be more or less rapidly reached depending on the quantity of rubidium in the diet. However, it is noticeable that the rubidium content in aphids from the control diet was different from zero. These aphids fed exclusively on a diet devoid of rubidium. Thus, traces of this element can be considered as the endogenous rubidium level acquired from the parental generation that fed on wheat seedlings
TABLE 2. Effect of rubidium content on host acceptance by female of A. rhopalosiphi. $0=$ control diet; $1.3=\operatorname{diet}$ supplemented with $1.3 \mathrm{mg} / \mathrm{ml}$ of $\mathrm{RbCl} ; 2.4$ = diet supplemented with $2.4 \mathrm{mg} / \mathrm{ml}$ of $\mathrm{RbCl}$.

\begin{tabular}{cccccc}
\hline $\begin{array}{c}\text { Rb content } \\
(\mathrm{mg} / \mathrm{ml})\end{array}$ & $\mathrm{n}$ & \multicolumn{2}{c}{$\begin{array}{c}\text { Acceptance ratio } \\
(\text { means } \pm \text { S.E. })\end{array}$} & \multicolumn{2}{c}{$\begin{array}{c}\text { Stinging ratio } \\
\text { (means } \pm \text { S.E.) }\end{array}$} \\
\hline 0 & 11 & 74.2 & 4.0 & 63.1 & 4.9 \\
1.3 & 11 & 74 & 4.8 & 57.8 & 5.2 \\
2.4 & 13 & 73.3 & 4.5 & 62.1 & 4.2 \\
\hline
\end{tabular}

in the laboratory, or from rubidium traces in the diet ingredients.

We have shown that rubidium is transferred from the host to the parasitoid. When $2400 \mathrm{ppm} \mathrm{RbCl}$ were incorporated to the diet, a mean of $50 \mathrm{ppb}$ of $\mathrm{Rb}$ and $20 \mathrm{ppb}$ was detected in the aphids and parasitoids, respectively. A proportion of rubidium may be lost in the honeydew or in the aphid cuticle. The transfer to the next parasitoid generation through oviposition could not be demonstrated probably because of the small amount of matter transmitted (egg and venom). In our case, females were mated with unmarked males. However, Knight et al. (1989) showed that there is a contribution of males to rubidium content in eggs of Platynota idaeusalis (Lepidoptera: Tortricidae). Unfortunately, for Aphidiine wasps, no information is available about the quantity of sperm that could be transferred to the host along with the female's venom injected to the host. The detection of rubidium in aphid stung by marked parasitoids would be valuable in dispersion studies, notably to evaluate the dispersion of adults by recapture methods, but also to determine the pattern of the progeny distribution among the host patches within the habitat. Marked larvae of Aphidius rhopalosiphi may be interesting for superparasitism studies. The intergenerational transmission of rubidium remains unresolved. That could be studied by raising the rubidium concentration in order to increase the detection in time. One way to raise the rubidium content in the parasitoid could be the incorporation of $\mathrm{RbCl}$ in the water-honey solution used to feed the adults. This was proved to be efficient for the radioactive marking of Trichogramma and Aphidius sp. through $\mathrm{P}^{32}$ supplemented honey (Quednau, 1960). In this way, the parasitoid could incorporate the marking through the larval nutrition (consumption of the aphid) and adult nutrition. Moreover, the transfer from the adult diet to the parasitoids' eggs should be more important in synovogenic than in pro-ovogenic species. However, increased concentrations may have some negative effects for the aphids or the parasitoids, even if several authors have shown that rubidium used in appropriate concentrations has no apparent negative effects (Stimmann et al., 1973; Graham \& Wolfenbarger, 1977; Van Steenwyk et al., 1978). The concentrations used in this study were chosen after preliminary tests that revealed an increase of aphid mortality on diets supplemented with high $\mathrm{RbCl}$ concentrations (up to $48.8 \mathrm{mg}$ $\mathrm{RbCl} / \mathrm{ml}$ of diet). We therefore used only the concentrations that had no effects on aphid survival and fecundity. Nevertheless, other tests with higher $\mathrm{RbCl}$ concentrations 
and other aphid species could be an interesting way to improve the transfer of the marking to the second generation of the parasitoid.

Rubidium affected the development times of the parasitoid inducing a delay in the mummification and in adult emergence, but larvae completed their development without apparent consequences. A negative effect of the rubidium on insect growth rate has been reported for Melanoplus sanguinipes (Orthoptera: Acrididae) (Woods \& Streett, 1996), Platynota idaeusalis (Lepidoptera: Tortricidae) (Knight et al., 1989) and Microplitis croceipes (Hymenoptera: Braconidae) (Hopper \& Woolson, 1991). It is possible that some physiological processes that take place during the early development of parasitoid larvae may be disturbed by replacement of the potassium by the rubidium. Indeed, we note that aphids fed on a rubidium diet were smaller in their early development but then grew more rapidly to become as large as control aphids.

Numerous studies on the effect of rubidium on longevity are available but the results are inconsistent mainly because of differences regarding to the tested species and rubidium concentrations. Jackson et al. (1988) noted that Anaphes ovijentatus (Hymenoptera: Mymaridae) has a shorter lifespan when its host was fed with an artificial diet containing $1000 \mathrm{ppm}$ of $\mathrm{RbCl}$. Similar results were obtained by Knight et al. (1989) on Platynota idaeusalis adults when the larvae were reared on an artificial diet with $6000 \mathrm{ppm}$ of rubidium. But, in their study, female survival was not significantly different when only 3000 ppm of rubidium were added to the diet. Stimmann et al. (1973) did not observe any effect on survival when Trichoplusia ni (Lepidoptera: Noctuidae) was fed with a diet containing up to $14000 \mathrm{ppm}$ of rubidium. In our results, females lived longer than males as observed by Hofsvang and Hagvar (1975) for Aphidius ervi and A. platensis. However, the $\mathrm{RbCl}$ concentration in the diet had no effect regarding to insect longevity. In the same way, acceptance behaviour was not affected, but the influence of rubidium on other stages of the parasitism behaviour remained to be tested, including habitat location (plant odour perception) and flight capabilities.

\section{CONCLUSIONS}

Artificial diets are an interesting alternative to directly incorporate rubidium to insects, without uncertainty about the assimilation of the element into the plant. It also constitutes a rapid method to mark aphid parasitoids through their hosts. This study proves that rubidium is transferred from the diet to the aphids and eventually to the parasitoids. Up till now, the use of trace elements remains the only valuable solution for small insects. However, in the case of field studies, local endogenous levels of rubidium need to be assessed before starting an experiment. Even though further studies are still needed for a transgenerational marking, this method for aphid parasitoids marking remains a useful tool for population biology studies (dispersion and spatial structure of population). Moreover, this should be used to mark aphid predators to broaden its application to the aphidophagous guild.
ACKNOWLEDGEMENTS. The authors would like to thank O. Lebbe and A. Isérentant for their help with the laboratory work and C. Salin and H. Colinet for their valuable comments on the manuscript, as well as the two anonymous reviewers. This paper is \#BRC064 of the biodiversity research centre.

\section{REFERENCES}

AuCLAIR J.L. 1965: Feeding and nutrition of the pea aphid, Acyrthosiphon pisum (Homoptera: Aphidae), on chemically defined diets of various $\mathrm{pH}$ and nutrients levels. Ann. Entomol. Soc. Am. 58: 855-875.

Berry W.L., Stimmann M.W. \& Wolf W.W. 1972: Marking of native phytophagous insects with rubidium: a proposed technique. Ann. Entomol. Soc. Am. 65: 236-238.

Cambier V., Hance T. \& De Hoffman E. 2001: Effects of 1,4-benzoxazin-3-one derivates from maize on survival and fecundity of Metopolophium dirhodum (Walker) on artificial diet. J. Chem. Ecol. 27: 359-370.

Fernandes O.A., Wright R.J., Baumgarten K.H. \& Mayo Z.B. 1997: Use of rubidium to label Lysiphlebus testaceipes (Hymenoptera: Braconidae), a parasitoid of greenbugs (Homoptera: Aphididae), for dispersal studies. Environ. Entomol. 26: 1167-1172.

Frazer B.D. \& Raworth D.A. 1974: Marking aphids with rubidium. Can. J. Zool. 52: 1135-1136.

Graham H.M. \& WolfenbaRger D.A. 1977: Tobacco budworm: labeling with rubidium in the laboratory. J. Econ. Entomol. 70: $800-802$.

Guillebeau L.P., All J.N., Nutter F.W. \& Kuhn C. 1993: Comparison of foliar and soil-drech applications of aqueous rubidium chloride solution to plants for marking feeding aphids (Homoptera: Aphidae). J. Entomol. Sci. 28: 370-375.

HAGLER R.J. \& JACKSON C.G. 2001: Methods for marking insects: current techniques and future prospects. Annu. Rev. Entomol. 46: 511-543.

Hofsvang T. \& Hagvar E.B. 1975: Duration of development and longevity in Aphidius ervi and Aphidius platensis (Hymenoptera: Aphidiidae), two parasites of Myzus persicae (Homoptera: Aphididae). Entomophaga. 20: 11-22.

Hopper K.R. \& Woolson E.A. 1991: Labeling a parasitic wasp, Microplitis croceipes (Hymenoptera: Braconidae), with trace elements for mark-recapture studies. Ann. Entomol. Soc. Am. 84: $255-261$.

JACKson C.G., Cohen A.C. \& Verdugo C.L. 1988: Labeling Anaphes ovijentatus (Hymenoptera: Mymaridae), an egg parasite of Lygus spp. (Hemiptera: Miridae), with rubidium. Ann. Entomol. Soc. Am. 81: 919-922.

Knight A.L., Hull L.A., Rajotte E.G. \& Fleischer S.J. 1989: Labeling tufted apple bud moth (Lepidoptera: Tortricidae) with rubidium: effect on development, longevity, and fecundity. Ann. Entomol. Soc. Am. 82: 481-485.

Legrand M.A., Salin C., Langer A. \& Hance T. 2004: Are mummy characteristics reliable indicators of diapause and cold tolerance in the parasitoid wasp Aphidius rhopalosiphi (Braconidae, Aphidiinae)? CryoLetters 25: 161-166.

Payne J.A. \& Wood B.W. 1984: Rubidium as a marking agent for the hickory shuckworm, Cydia caryana (Lepidoptera: Tortricidae). Environ. Entomol. 13: 1519-1521.

Quednau W. 1960: Radioactive Markierung von Schlupfwespen. Atompraxis 6: 427-431.

Qureshi J.A., Bushman L.L., Ramaswamy S.B., Throne J.E. \& WhaleY P.M. 2004: Evaluation of rubidium chloride and cesium chloride incorporated in a meridic diet to mark Diatraea grandiosella (Lepidoptera: Crambidae) for dispersal studies. Environ. Entomol. 33: 487-498. 
Southwood T.R. 1969: Ecological methods with particular reference to the study of insect populations. In Berry W.L., Stimmann M.W. \& Wolf W.W.: Marking of native phytophagous insects with rubidium: a proposed technique. Ann. Entomol. Soc. Am. 65: 236-238.

StimmanN M.W. 1974: Marking insects with rubidium: imported cabbageworm marked in the field. Environ. Entomol. 3: 327-328.

Stimmann M.W., Wolf W.W. \& Berry W.L. 1973: Cabbage loopers: biological effects of rubidium in the larval diet. $J$. Econ. Entomol. 66: 324-326.
VAN STEEnwyk R.A. 1991: The use of elemental marking for insect dispersal and mating competitiveness studies: from laboratory to the field. Southwest. Entomol. 14: 15-24.

Van Steenwyk R.A., Ballmer G.R., Page A.L. \& Reynolds H.T. 1978: Marking pink bollworm with rubidium. Ann. Entomol. Soc. Am. 71: 81-84.

Woods S.A. \& Streett D.A. 1996: Assimilation of rubidium by Melanoplus grasshoppers (Orthoptera: Acrididae). Environ. Entomol. 25: 906-911.

Received September 21, 2004; revised and accepted February 17, 2005 